\title{
Modulación duobinary en aplicaciones SI-POF
}

\author{
J. Aguirre, C. Sánchez-Azqueta, E. Guerrero, C. Gimeno, S. Celma \\ Grupo de Diseño Electrónico (GDE) \\ Instituto de Investigación en Ingeniería de Aragón (I3A). \\ Universidad de Zaragoza, Mariano Esquillor s/n, 50018, Zaragoza, Spain. \\ Tel. +34-976762707, Fax +34-976762043, e-mail: jag@unizar.es
}

\begin{abstract}
En comunicaciones serie de alta velocidad NRZ es la técnica de modulación más extendida. Sin embargo, la modulación denominada duobinary ofrece buenos resultados en canales con un roll-off pronunciado, aumentando la velocidad de transmisión con arquitecturas simples. Este trabajo demuestra que esta técnica puede resultar ventajosa para transmisión serie multigigabit por fibra ópica de plástico.
\end{abstract}

\section{Introducción}

La creciente demanda de sistemas de comunicaciones con tasas de bits cada vez más elevadas en entornos domésticos ha potenciado el desarrollo de sistemas eficaces de bajo coste y bajo consumo.

Uno de los frentes que más posibilidades nos abren a la hora de conseguir tasas de bits elevadas es el uso de diferentes técnicas a la hora de modular las señales.

\section{Modulación duobinary}

Tradicionalmente, la modulación non-return to zero (NRZ) es la técnica de modulación más extendida por ser la más sencilla de procesar tanto en el emisor como en el receptor, lo que redunda en niveles de consumo mínimos.

Uno de los principales factores que producen errores en la transmisión digital es la llamada interferencia intersímbolo (ISI). Esto es, el solapamiento que se produce entre símbolos consecutivos como consecuencia de la distorsión de la señal producida por la limitación en banda de los canales.

La técnica duobinary, propuesta por primera vez en los años 60 [1], es una opción interesante en estos casos, ya que deliberadamente introduce ISI de manera controlada, con el objetivo de poder eliminarlo en el receptor, y recuperar así la señal limpia [2].
Para introducir de manera correcta el ISI en nuestra señal, es necesario implementar en el emisor un precodificador, cuya estructura más sencilla puede verse en la Fig. 1, y que únicamente requiere de una puerta AND y un divisor de frecuencia. A la salida de este precodificador, obtenemos otra señal de dos niveles (señal PRECOD de la Fig. 2)

Cuando esta señal atraviesa un canal real (cuyo módulo de la respuesta frecuencial tienen siempre forma de filtro pasa baja), la distorsión lineal provoca una visible deformación en la señal. Lo que aparentemente puede parecer una señal degradada es en realidad una señal de tres niveles perfectamente diferenciados. Con ayuda únicamente de dos comparadores y una puerta XOR puede decodificarse la señal DUO para volver a recuperar la señal NRZ que teníamos a la entrada del sistema.

Si la secuencia de bits puede considerarse aleatoria, la densidad espectral de la señal DUO es conocida, y coincide en forma funcional con la densidad espectral de la señal NRZ $\left(\operatorname{sinc}^{2}\right)$, pero compactada en la mitad de intervalo frecuencial [2]. Esto implica que, con modulación duobinary puede conseguirse el doble de velocidad de bits que con NRZ, sin aumentar la complejidad de la arquitectura del transceptor. Sin embargo, la relación señal-ruido se reduce, por lo que serán necesarios receptores más sensitivos.

\section{Aplicación a POFs}

En la literatura hay varias comparativas entre diferentes tipos de modulación, pero no se aporta un criterio definitivo. La modulación óptima depende en cada caso de la forma de la función de transferencia del canal y de la velocidad de transmisión deseada [2]. Por nuestra experiencia estamos en condiciones de afirmar que la modulación duobinary es preferible a NRZ en canales con un roll-off superior a los $60 \mathrm{~dB} / \mathrm{dec}$.

La Fig. 3 muestra la respuesta de una fibra óptica de plástico (SI-POF) de $50 \mathrm{~m}$ así como la unión 
entre este canal y un receptor con ecualización analógica [3]. Como puede verse, el roll-off de la POF es bajo ( 40 dB/dec), pero aumenta considerablemente al añadir el ecualizador, haciéndolo adecuado para trabajar con modulación duobinary.

Las Fig. 4(a) y 4(b) muestran los diagramas de ojo de una señal a 3 Gbps a través del sistema completo POF+ecualizador descrito en [3]. En la Fig. 4(b), lo que aparentemente es un ojo cerrado (si considerásemos que la señal fuese de dos niveles) es en realidad un ojo abierto si tenemos en cuenta que se trata de una señal duobinary de tres niveles. La Fig. 4(c) muestra la señal decodificada. Es decir, se ha conseguido aumentar la velocidad de transmisión del canal con respecto a [3].

\section{Conclusión}

Se ha demostrado que para canales POF, la modulación duobinary consigue duplicar la velocidad de transmisión respecto a la modulación NRZ, manteniendo la misma tasa de error. Esto se

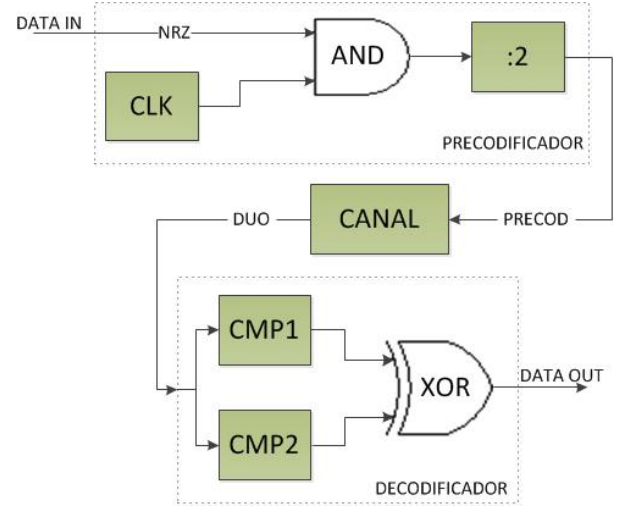

Fig. 1. Precodificador y decodificador duobinary.

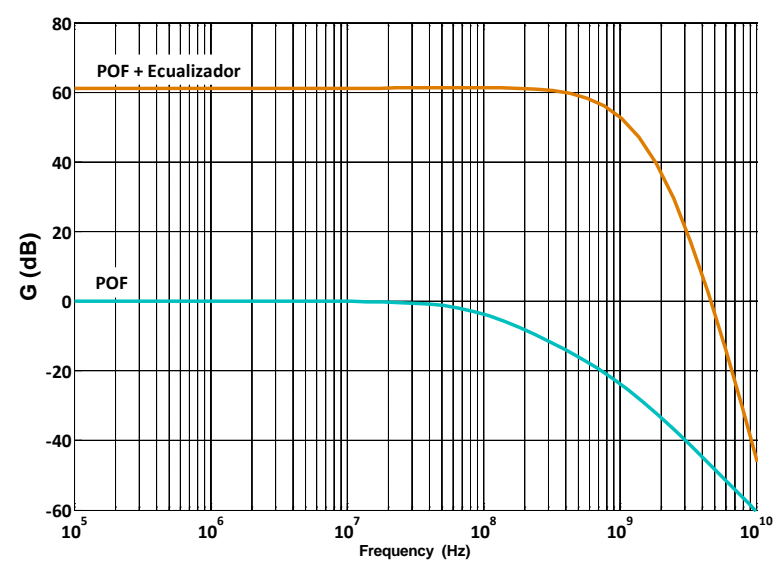

Fig. 3. Respuesta frecuencial (suavizada) de SI-POF de 50 m sin y con ecualización. consigue introduciendo ISI en la señal de manera controlada, de modo que pueda eliminarse en el receptor, recuperando así la secuencia de bits original. El empleo de esta técnica de modulación puede ayudar a superar las restrictivas limitaciones de banda ancha en sistemas de comunicaciones con fibra óptica de plástico.

\section{REFERENCIAS}

[1]. LENDER, A. The Duobinary Technique for HighSpeed Data Transmission. IEEE Transactions on Consumer Electronics. 1963, 82(2), 214-218.

[2]. LEE, J., CHEN, M. and WANG, H. Design and Comparison of Three 20-Gb/s Backplane Transceivers for Duobinary, PAM4 and NRZ Data. IEEE Journal of Solid-State Circuits. 2008, 43(9), 2120-2133.

[3]. GIMENO, C., ALDEA, C., CELMA, S. and AZNAR, F. Cost-Effective 1.25-Gb/s CMOS Receiver for 50-m Large-Core SI-POF Links. IEEE Photonics Technology Letters. 2012, 24(6), 485487.

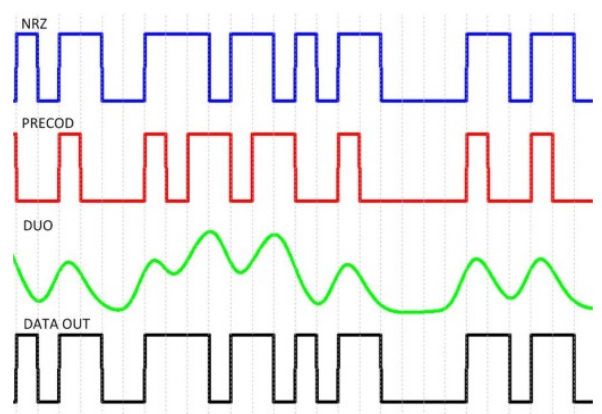

Fig. 2. Formas de onda de un sistema con modulación duobinary.

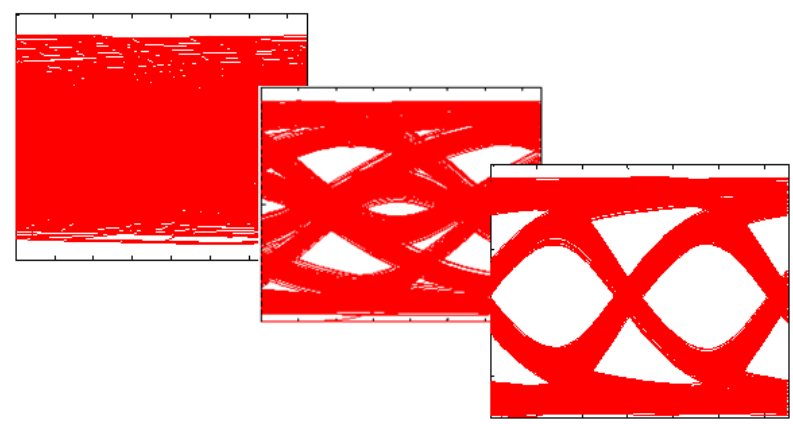

(a)

(b)

(c)

Fig. 4. Diagrama de ojo para 3 Gbps DUO sobre: (a) POF 50 m (b) POF 50m + ecualizador, (c) Salida del decodificador. 